\title{
A Clean and Sustainable Future
}

\author{
Mingwei Jiang1, a \\ ${ }^{1}$ School of Finance, Shanghai University of Finance and Economics, Shanghai, China \\ a794419010@qq.com
}

Keywords: Analytic Hierarchy Process; Energy usage; Grey Relation Analysis; Linear Programming

\begin{abstract}
In this paper, the four states along the U.S. border with Mexico are suggested to form an energy compact. To derive a settlement, two major model problems are built and solved. (1)Combine Analytic Hierarchy Process(AHP), an Objective Evaluation Model(OPM) based on Max-Entropy and Grey Relation Analysis(GRA) to derive Sustainability Index(SI) for evaluation of energy usage of each state; (2)Integrate SI with Linear Programming Model(LPM) to design optimal goal for the compact. Finally, a development strategy of $28.6 \%$ Hydroelectricity, 34.5\% Wind power, $16.3 \%$ Biomass, 20.6\% Geothermal is given as the compact's goal.
\end{abstract}

\section{Introduction}

Entering the 21st century, the world has witnessed the drastic climate change brought by previous unscrutinized use of dirty energy. Substituting dirty energy with clean and renewable ones is one effective way to lead us into the clean and bright future.

A good way to achieve this is to form an energy compact between adjacent states, because energy production and consumption are not only about developing some kind of energy technology. Instead, they are more about energy structure and energy program, which is the responsibility of the government department. In 1970, 12 western states in the U.S. has formed the Western Interstate Energy Compact (WIEC), whose mission focused on fostering cooperation between these states for the development and management of nuclear energy technologies. Along the U.S. border with Mexico, there are four states-California (CA), Arizona (AZ), New Mexico (NM), and Texas (TX)-that can emulate WIEC to form a realistic new energy compact focused on increased usage of cleaner, renewable energy sources.

\subsection{Literature Review}

Many scholars have studied energy evaluation and decision making, which provides us with a lot of references.

Carley S. develop decoupling theory to deeply analyze the dependency between economic development and the various energy consumption of each state. ${ }^{[1]} \mathrm{Hong} \mathrm{Li}$ et al. establish the Renewable Energy Assessment and Optimization (REAO) based on the analytical hierarchy process (AHP) ,where the ranked results of renewable energies are obtained, and linear programming, by which the optimal structure of 6 types of renewable energy is derived. ${ }^{[2]}$ Evans, et al. propose the evaluation indicators of renewable energy power generation technology: generation cost, greenhouse gas emissions and energy efficiency, technical feasibility, land occupation, water consumption and social impact. ${ }^{[7]} \mathrm{Heo}$, et al. set up five core indicators of technology, market, economy, environment and policy. Applying analytic hierarchy process (AHP) and fuzzy-AHP, the paper evaluates the popularization policy of new energy in Korea. ${ }^{[18]}$

\subsection{Assumptions and Justifications}

\subsubsection{Cleaner and renewable energy refers to sustainable energy}

Former US president Obama once deemed nuclear power ,natural gas and clean coal under the term of clean energy as well. ${ }^{[3]}$ On the contrary, however, sustainable energy, including 
hydroelectricity, solar energy, wind energy, geothermal energy, bioenergy and so on, is well defined and is often referred as a synonym of clean energy. ${ }^{[4]}$

\subsubsection{Nuclear power is not renewable}

Statutory definitions of renewable energy usually exclude many present nuclear energy technologies, with notable exceptions in the states of Utah, and Arizona in the United States Dictionary sourced definitions of renewable energy technologies often omit or explicitly exclude mention to every nuclear energy source.

\section{Evaluation Model and Sustainability Index}

\subsection{Analytic Hierarchy Process(AHP)}

AHP is widely used for quantifying qualitative problems when making decisions. First, according to the relative importance of the first order indicators, the comparison matrix is determined(for instance, ' 2 ' indicates that one indicator is as twice important as another indicator), the weights of the first order indicators can be calculated by the comparison matrix; then the weights of the second order indicators are allocated under the first order indicator; and through consulting the literature materials ${ }^{[2]}$, the specific value of indicators, called assessment matrix, is determined. Finally, the weights of indicators(row vector) and the assessment matrix are multiplied to get the score of each sustainable energy. In fact, we use comprehensive weights instead of just subjective weights( See section 2.3).

\subsection{First and Second Order Indicators}

Economic Indicator, Technical Indicator, Resource Indicator\& Environment indicator are chosen as first order indicators in consideration of existing literature and the energy category in this paper.

Economic Indicators--(a)General Cost: including cost of generating electricity( refers to the average level of domestic renewable energy industry) and external cost( refers to environmental losses caused by renewable energy's generating electricity in its life cycle).[9,15](b)Installed Capacity: reflecting the status quo of the development and utilization of renewable energy and affecting the development of renewable energy.

Technical Indicators--The feasibility and limitations of technology determine the development of renewable energy.(a)Processing and Converting Efficiency of Energy: reflecting the efficiency of processing and conversing energy. Efficiency of renewable energy varies due to different standard of equipment and technology.( The data are collected from[6].)(b)Maturity of Technology: It is a qualitative index, reflecting the current application of generating electricity of renewable energy.

Resource Indicator--(a)Distribution Characteristics.It is a qualitative index, reflecting the characteristics of the distribution of renewable energy. Good distribution of resources should match that the region with a large amount of energy should be close to the power load center.

Environment indicator--(a)major environment index: Although renewable energy hardly has carbon emission, other links in production chain, including exploit and transport the raw material etc. will lead to carbon emission. Weighted mean method is applied to the data from relevant international institution(such as IPCC) and literature.(b)other environmental impacts. It is a qualitative index. For example, wind power will pose a threat on birds and bring about noise.

Table 1 Comparison Matrix of AHP

\begin{tabular}{lllll}
\hline indicator & economy & technique & resource & environment \\
\hline economy & 1.00 & 1.25 & 1.00 & 1.33 \\
technique & 0.80 & 1.00 & 0.80 & 1.25 \\
resource & 1.00 & 1.25 & 1.00 & 1.33 \\
environment & 0.75 & 0.80 & 0.75 & 1.00 \\
\hline
\end{tabular}


Table 2 Subjective Weights of the Indicators( 2009)

\begin{tabular}{|c|c|c|c|}
\hline First order indicator & $\begin{array}{l}\text { Weight of first order } \\
\text { indicator }\end{array}$ & Second order indicator & $\begin{array}{l}\text { Weight of second order } \\
\text { indicator }\end{array}$ \\
\hline \multirow[t]{2}{*}{ economy } & 0.2813 & $\begin{array}{ll}\text { General } & \text { cost } \\
\text { (USD/kWh) } & \end{array}$ & 0.176 \\
\hline & & $\begin{array}{l}\text { Installed } \\
\text { capacity(MW) }\end{array}$ & 0.115 \\
\hline \multirow[t]{2}{*}{ technique } & 0.2344 & $\begin{array}{l}\text { processing and } \\
\text { conversing efficiency } \\
\text { of energy }(\%)\end{array}$ & 0.114 \\
\hline & & Maturity of technology & 0.167 \\
\hline resource & 0.2813 & $\begin{array}{l}\text { distribution } \\
\text { characteristics }\end{array}$ & 0.170 \\
\hline \multirow[t]{2}{*}{ environment } & 0.2030 & $\mathrm{CO}_{2}$ emission(g/kWh) & 0.110 \\
\hline & & $\begin{array}{l}\text { other environmental } \\
\text { impacts }\end{array}$ & 0.172 \\
\hline
\end{tabular}

Table 1 represents the comparison matrix of AHP. Table 2 shows the subjective weights of the indicators(namely AHP weights).

\subsection{Objective Evaluation Model}

After the subjective weights analysis based on Analytical Hierarchy Process(AHP), Grey Relation Analysis (GRA) is integrated with Max-Entropy Method ${ }^{[5]}$ to evaluate problem of the analysis of objective weights so as to exploit the hidden information better.

Grey relational Analysis (GRA) is a multi-factor analytical method. It describes the relationship between the factors in line of the gray relation degree. It utilizes the degree of similarity between the geometrical shapes to judge the extent to which the sequences are related. The closer the curve is, the closer the relationship is, vice versa.

Max-Entropy Method was first established by E.T. Jaynes in 1957. He proved a natural correspondence between statistical mechanics and information theory. In information theory, information entropy signifies the amount of the information, which inspires a new approach in exploring information in statistical analysis. Based on Max-Entropy, speculations can be made about the possible distributional model and lurking information can be fully exploited ${ }^{[5]}$.

Calculation of Correlation Coefficient

The gray correlation coefficient of $x_{0}$ and $x_{i}$ is $\gamma_{i}=\frac{\min \min \left|x_{0}(k)-x_{i}(k)\right|+\rho \max \max \left|x_{0}(k)-x_{i}(k)\right|}{\left|x_{0}(k)-x_{i}(k)\right|+\rho \max \max \left|x_{0}(k)-x_{i}(k)\right|}$

The degree of relationship between the indexes can be quantified by Grey Relation Coefficients. Then, we quantify the inner-relation between the sequence elements.

$$
\zeta_{i}(k)=\frac{\gamma_{i}}{\sum_{i=1}^{n} \gamma_{i}} \quad \mathrm{Q}(\mathrm{k})=\frac{1}{n} \sum_{i=1}^{n}\left(\zeta_{i}(k)-\frac{1}{n}\right)^{2}
$$

The range of weight can be expressed as below.

$$
w_{k} \in\left[\min \left(\zeta_{i}(k)\right), \max \left(\zeta_{i}(k)\right)\right] i=1,2, \ldots, n k=1,2, \ldots, m
$$

The range of the variance of the weight should also be taken into consideration and its range is also directly related to the Eq. 3.

$$
\frac{1}{m} \sum_{k=1}^{m}\left(w_{k}-\frac{1}{m}\right)^{2} \in(\min (Q(k)), \max (Q(k))) \quad k=1,2, \ldots, m
$$

Now a Max-Entropy Method of the index's weights can be constructed as follows. It is equivalent to an Optimal Programming Problem (OOP) with a proved optimal solution. 


$$
\begin{gathered}
\max \quad F=-\sum_{k=1}^{m} w_{k} \ln w_{k} \text { s.t. } \sum_{k=1}^{m} w_{k}=1 w_{k} \in(0,1) w_{k} \in\left[\operatorname { m i n } \left(\zeta_{i}(k), \max \left(\zeta_{i}(k)\right]\right.\right. \\
\frac{1}{m} \sum_{k=1}^{m}\left(w_{k}-\frac{1}{m}\right)^{2} \in(\min (Q(k)), \max (Q(k)))
\end{gathered}
$$

From the analysis above, we can finally derive both the AHP weights $v$ and the Max-Entropy Method \& GRC weights w. The comprehensive weights $Z$ is expressed as:

$$
z_{j}=\frac{w_{j} v_{j}}{\sum_{j} w_{j} v_{j}}
$$

\subsection{Sustainability Index(SI):}

The Sustainability Index(SI) of each kind of energy is defined as the comprehensive weights(row vector ) multiplying with assessment matrix .Multiply SI with the ratio of sustainable energy, we can get State Score (shown in table 3)for each states:

$$
\text { StateScore }=\sum_{j=1}^{5} S I_{j} * \text { Rat }_{j} \text {. }
$$

Where Rat $_{j}$ represents the share of sustainable energy $j$ in the total energy consumption( in the order of Wind, Hydro, Solar, Biomass, Geothermal)

Table 3 State Score( 2017)

\begin{tabular}{lrrrccc}
\hline SI & Wind & Hydro & Solar & Biomass & Geothermal & State Score \\
\hline AZ & 0.86 & 0.95 & 0.71 & 0.77 & 0.7 & 0.063 \\
CA & 0.82 & 0.85 & 0.79 & 0.72 & 0.75 & 0.072 \\
NW & 0.89 & 0.82 & 0.79 & 0.76 & 0.7 & 0.042 \\
TX & 0.93 & 0.81 & 0.75 & 0.76 & 0.7 & 0.024 \\
\hline
\end{tabular}

\subsection{Correctness Check}

Clean Edge's State Index ${ }^{[13]}$ is an existing influential index describing the degree of sustainable energy usage. In 2017, Clean Edge's State Index rank these four states in the order of CA,NW,TX,AZ(with respective score of 92.0, 48.1, 42.0, 32.8). Comparing the State Index with State Score, we can find that the order of states are almost the same, showing the model's high correctness, except an major discrepancy concerning AZ. Considering the fact that State Index are given in 2017 while our index based on data of 2009, the discrepancy may result from (1) policy changes during this period; (2) in the beginning AZ ranks $2^{\text {nd }}$ due to its abundant hydroelectricity resources but was then out-developed by other states in sustainable energy usage. With sufficient data, we have reason to believe this discrepancy can be eliminated.

\section{Linear Programming Model}

\subsection{Model Building}

Although in the short term, the cost of development of sustainable energy is comparably higher, it has brought the benefit of resource and environment. In light of this, in the following programming model constructed for deriving the optimal proportion of each sustainable energy, constraints are designed in four aspects: cost, technique, resource and carbon emission.

In this model, the four states are considered as a whole in order to simulating the reach the optimal goal through . The specific value of assessment matrix are revised to the prediction value when using SI of 2025 and 2050( see Table 4). We only concentrate on the inner structure of sustainable energies: 
$W_{i}^{d}=\frac{T A_{i}^{d}}{\sum_{i} T A_{i}^{d}} \quad$ Where $T A_{i}^{d}$ refers to the quantity of sustainable energy i consumption in year $\mathrm{d}$.

The explanation of constraints:1)All the weights $(W)$ of the renewable energy is larger or equals to 0(2)The total weight accumulated equals to 1(3)The higher the renewable energy rank, the larger proportion it will achieve in the future (4) Cost constraint: Given that it is inevitable that the development of renewable energy will raise the cost (such as building new energy equipment) compared to the previous situation, the optimized future average cost of renewable energy will lower than that of the current level.(5)Technical constraint: The optimized average indexes of the prospect of the development of future techniques are higher than that of the current level so that the development of the techniques of renewable energy is feasible. Moreover, the future index of technique maturity should be higher than that of the current level so that the current mature techniques are utilized efficiently.(6) Carbon emission constraint: make the carbon emission ( $\left.\mathrm{CO}_{2}\right)$ of total future renewable energy lower than that of the current level. (7)Take into account that the renewable energy should be endowed with balanced and overall development, the proportion of the renewable energy in the future should be higher than $3 \%$.

The programming model is applied to two scenarios.

Table 4 Assessment Matrix(2025/2050)

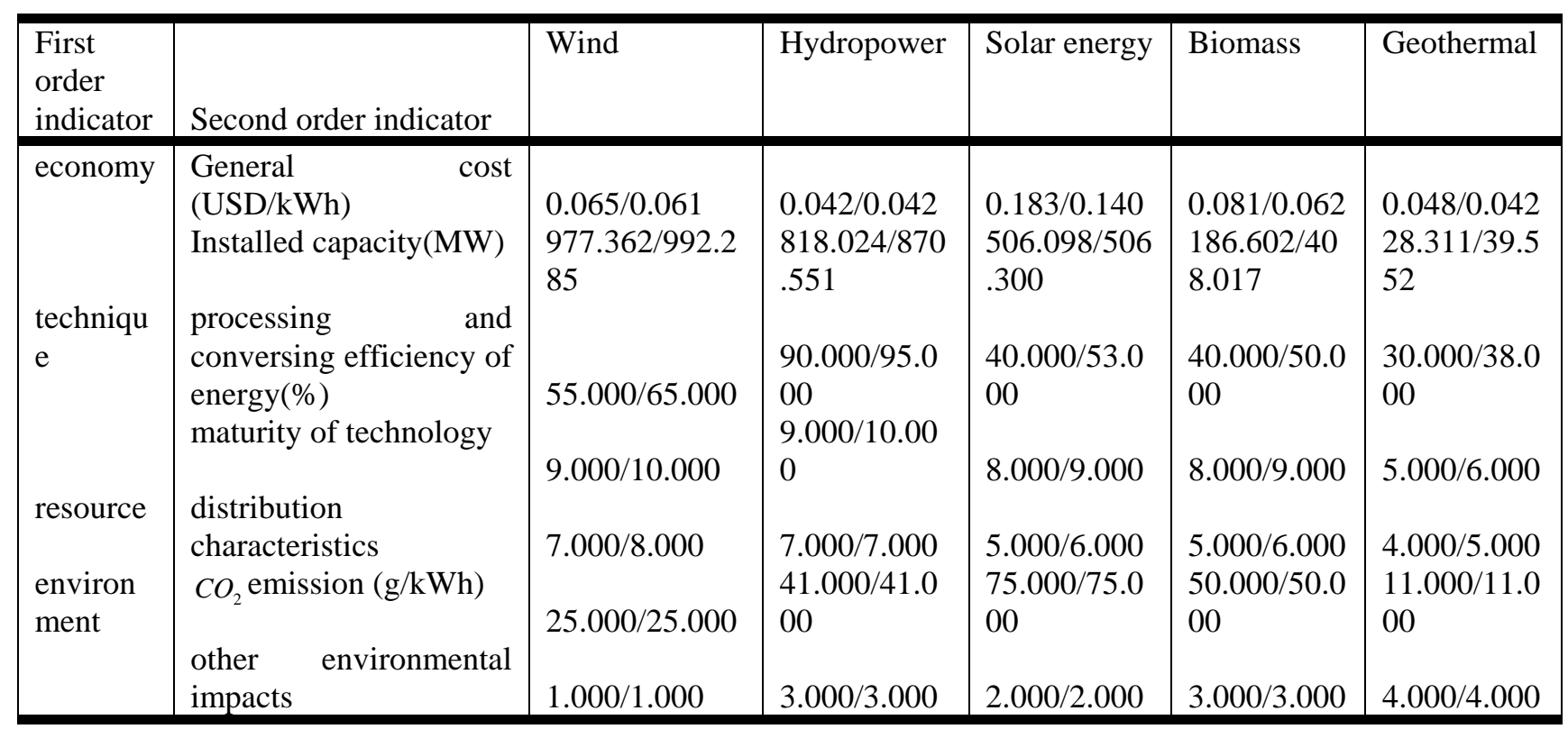

\subsection{Scenario 1}

Scenario 1 regard 2009 as base year and make the plan of structure of sustainable energy for 2025.

$$
\begin{aligned}
& \max O\left(W_{1}^{2025}, W_{2}^{2025}, \ldots, W_{5}^{2025}\right)=\sum_{i=1}^{5} W_{i}^{2025} E_{i}^{2025} \quad i=1,2, \ldots, 5 \text { s.t. } \quad W_{i}^{2025} \geq 0 \\
& \sum_{i} W_{i}^{2025} \leq 1 \quad \sum_{i} W_{i}^{2025} C_{i}^{2025} \leq \sum_{i} \overline{W_{i}^{2009} C_{i}^{2009}} \quad \sum_{i} W_{i}^{2025} T_{i}^{2025} \geq \sum_{i} \overline{W_{i}^{2009}} \overline{T_{i}^{2009}} \\
& \sum_{i} W_{i}^{2025} \operatorname{Tm}_{i}^{2025} \geq \sum_{i} \overline{W_{i}^{2009}} \overline{\operatorname{Tm}_{i}^{2009}} \quad \sum_{i} W_{i}^{2025}\left(\mathrm{CO}_{2}\right)_{i}^{2025} \leq \sum_{i} \overline{W_{i}^{2009}}\left(\mathrm{CO}_{2}\right)_{i}^{2009} \quad W_{i}^{2025} \geq 0.03
\end{aligned}
$$

Take per unit of total renewable energies into account: $E_{i}^{d}$ refers to the score that sustainable energy i get in year d, which are determined by the evaluation model mentioned above; $C_{i}^{d}$ refers to the general cost of sustainable energy $\mathrm{i}$ in year $\mathrm{d}$; $T_{i}^{d}$ refers to the development of technique of sustainable energy $\mathrm{i}$ in year $\mathrm{d}$; $T m_{i}^{d}$ refers to the technique maturity of sustainable energy $\mathrm{i}$ in year $\mathrm{d} ;\left(\mathrm{CO}_{2}\right)_{i}^{d}$ refers to carbon emission of sustainable energy i in year d. The data of the notations with a 
line such as $\overline{W_{i}^{2009}}$ are given or searched and the value of the notations without a line such as $\operatorname{Tm}_{i}^{2025}$ is predicted by the average growth rate among previous years or Verhulst model.

Result: our model suggest a development strategy of 35.6\% Hydroelectricity, 37.8\% Wind power, 16.4\% Biomass, $10.2 \%$ Geothermal.

\subsection{Scenario 2}

Scenario 2 regards 2025 as base year and make the plan of structure of sustainable energy for 2050 . The meaning of the notations in scenario 2 are similar to scenario 1 and the distinct difference is that the data of the notations with a bar such as $\overline{W_{i}^{2025}}$ are determined by the results obtained in scenario 1 .

Result: our model suggest a development strategy of 28.6\% Hydroelectricity, 34.5\% Wind power, 16.3\% Biomass, 20.6\% Geothermal.

\section{Discussion}

Integrate the above results, CA should lead and contribute to the development of sustainable energy of the whole union. Given that the development of the structure of the sustainable energy should be balanced, solar power, of which the installed capacity is lower in the whole union, should be exploit with priority. The energy department of the four states government should coordinate on the allocation of energy production to each states to fulfill the compact goal of optimal energy structure. For example, AZ is abundant in hydro power, so allocate hydroelectricity production to AZ while let CA fully exploit its solar power advantages.

\section{References}

[1] Carley S. State renewable energy electricity policies: An empirical evaluation of Effectiveness [J]. Energy Policy, 2009, 37(8): 3071-3081.

[2] Hong Li, Liang Dong, \& Hongxia Duan. Comprehensive Evaluation and Structure Optimization of China Renewable Energy Development. Resources Science[J]. Resources Science, 2011(03):431-440.

[3]

Information

on http://www.nbcnews.com/id/41280794/ns/us_news-environment/t/obamas-definition-clean-ener gy-broad-one/\#.Wn8Qlvlsj3R

[4] Information on https://en.wikipedia.org/wiki/Sustainable_energy

[5] Konig R, Renner R, Schaffner C. The Operational Meaning of Min- and Max-Entropy[J]. IEEE Transactions on Information Theory, 2009,55(9):4337-4347.

[6] Boqiang Lin. Energy demand and energy price movements under the crisis and their impact on the macroeconomy[J]. Financial Research, 2010,(01), 46-57

[7] Annette E., Vladimir S., Tim, J. E.. Assessment of sustainability indicators for renewable energy technologies[J]..Renewable and Sustainable Energy Reviews， 2009，13:1082-1088.

[8] Eunnyeong Heoa, Jinsoo Kima, Kyung-Jin Boo. Analysis of the assessment factors for renewable energy dissemination program evaluation using fuzzy AHP[J]. Renewable and Sustainable Energy Reviews, 2010, 14(8): 2214-2220. 